\title{
Effect of angiotensin I-converting enzyme and $\alpha$-actinin-3 gene polymorphisms on sport performance
}

\author{
TUBA GUNEL ${ }^{1}$, ECE GUMUSOGLU ${ }^{1}$, MOHAMMAD KAZEM HOSSEINI $^{1}$, \\ EDA YILMAZYILDIRIM ${ }^{1}$, ISMAIL DOLEKCAP ${ }^{1}$ and KILIC AYDINLI ${ }^{2}$ \\ ${ }^{1}$ Department of Molecular Biology and Genetics, Faculty of Science, Istanbul University, \\ Istanbul 34134; ${ }^{2}$ Medicus Health Center, Istanbul 34365, Turkey
}

Received September 16, 2013; Accepted February 5, 2014

DOI: $10.3892 / \mathrm{mmr} .2014 .1974$

\begin{abstract}
Genetic polymorphism is considered to be associated with human physical performance. The angiotensin I-converting enzyme insertion/deletion (ACE I/D) and the $\alpha$-actinin-3 gene (ACTN3) R577X polymorphisms have been widely investigated for such associations, and functional ACE I/D and ACTN3 R577X polymorphisms have been associated with sprinter performance. The aim of this study was to determine the effect of these polymorphisms on sport performance among 37 elite athletes and 37 healthy controls. The ACE II genotype was identified in $32.43 \%$ of the control group and $8.11 \%$ of elite athletes, the DD genotype in $37.84 \%$ of the control group and $51.35 \%$ of the elite athletes, and the ID genotype in $29.73 \%$ of the control group and $40.54 \%$ of the elite athletes. With regard to the ACTN3 gene, the XX genotype, which confers an advantage for endurance activities, was identified in $10.81 \%$ of the control group and $35.14 \%$ of the elite athletes. The XX genotype was observed more frequently than the RR genotype (advantageous for sprinting), which was identified in $2.70 \%$ of the control group and $10.81 \%$ of elite athletes. The RX genotype (observed in $86.48 \%$ of the control group and in $54.05 \%$ of the elite athletes) was the most common genotype of the individuals in the present study. The study showed that ACTN3 and ACE gene polymorphisms have an effect on muscle power; however, larger studies are required.
\end{abstract}

\section{Introduction}

Genetics is involved in determining the athletic ability of an individual. A large number of studies have revealed various associations among specific gene polymorphisms, physical ability in various sport fields, and different ethnicities and genders (1). Two genes which have been extensively investigated

Correspondence to: Dr Tuba Gunel, Molecular Biology and Genetics, Faculty of Science, Istanbul University, Vezneciler Street, Istanbul 34134, Turkey

E-mail: gunel@istanbul.edu.tr

Key words: polymorphism, sport performance, athletic ability in association with athletic ability are angiotensin I-converting enzyme (ACE) and $\alpha$-actinin-3 (ACTN3). ACE is a key component of the renin-angiotensin-aldosterone system, generating the vasoconstrictor hormone angiotensin II and degrading the vasodilator kinins (2). The ACE I/D polymorphism was the first specific gene variant to be associated with human physical performance (3). A variation in the structure of the human ACE gene (17q22-q24) has been reported in which the insertion (I) variant was associated with lower ACE levels than the deletion (D) variant (4). An excess of the I allele has been associated with certain aspects of endurance performance $(5,6)$. The I allele is functionally associated with reduced ACE serum levels and activity. This allele is considered a favourable mutation as lower ACE activity results in less vasoconstriction and thus an increased delivery of oxygenated blood to the working muscles. Therefore, individuals that possess an I allele or the II genotype are thought to possess a greater advantage in endurance activities, including running, cycling and swimming, where the demand for oxygen is crucial. In 2009, Ahmetov et al showed that the ACE D allele was associated with greater strength and muscle volume at baseline and an increased percentage of fasttwitch muscle fibres. In addition, the D allele was shown to be associated with elite power athlete status (6).

It is generally accepted that muscle fibre composition may influence physical performance. The ACTN3 gene R577X polymorphism is suspected to be one of the contributing gene variations in the determination of muscle fibre type composition and athletic status (7). The $\mathrm{C}>\mathrm{T}$ polymorphism at nucleotide position 1747 in the ACTN3 coding sequence converts an arginine (R) to a stop codon (X) at residue $577(8)$. This variation generates two different versions of the ACTN3 gene common in the general population: The $577 \mathrm{R}$ allele is the normal functional version of the gene, whereas the $577 \mathrm{X}$ allele contains a sequence change that prevents the production of functional $\alpha$-actinin-3 protein (9). Homozygosity for the nonsense mutation, $\mathrm{X} / \mathrm{X}$, within ACTN3 results in $\alpha$-actinin-3 deficiency; however, it does not result in an abnormal muscular phenotype $(10,11)$. It has also been suggested that the $\mathrm{X}$ allele may confer an advantage during endurance events $(5,11,12)$. The findings of Yang et al (11) determined that the ACTN3 $\mathrm{R} / \mathrm{R}$ genotype is over-represented and the ACTN3 X/X genotype under-represented in power-oriented (including sprint) athletes, in comparison with controls. 
Table I. ACE and ACNT3 primer sequences.

Primer

ACE forward

ACE reverse

ACTN3 forward

ACTN3 reverse
Sequence

\author{
5'-CTGGAGACCACTCCCATCCTTTCT-3' \\ 5'-GATGTGGCCATCACATTCGTCAGAT-3' \\ 5'-CTGTTGCCTGTGGTAAGTGGG-3' \\ 5'-TGGTCACAGTATGCAGGAGGG-3'
}

ACE, angiotensin I-converting enzyme; ACNT3, $\alpha$-actinin-3.

The present study investigated the effect of ACE and ACTN3 gene polymorphisms in 37 elite athletes and 37 healthy controls to identify the potential correlations between genotype and physical performance.

\section{Materials and methods}

Ethical approval. The study was approved by the Ethics Committee of Istanbul University (Istanbul, Turkey; project no. 2011/2115-897).

Participants. A total of 37 healthy control individuals, aged

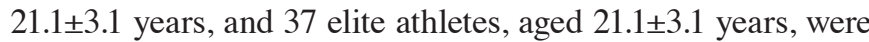
involved in the present study. The control individuals were not engaged in physical activity on a regular basis. Written informed consent was obtained from the patient/the family of the patients.

Genotyping. Molecular genetic analyses were performed using DNA samples, which were obtained from peripheral EDTA-treated blood with a DNA Extraction kit (Agilent Technologies, Inc., Santa Clara, CA, USA) according to the manufacturer's instructions. The ACE and ACTN3 polymorphisms were amplified using polymerase chain reaction (PCR). The ACE ID polymorphism PCR was conducted using the ACE forward and reverse primers (Table I; Tib MolBiol Syntheselabor GmbH, Berlin, Germany). PCR was performed by one cycle of denaturation at $95^{\circ} \mathrm{C}$ for $3 \mathrm{~min}$, annealing at $55^{\circ} \mathrm{C}$ for $50 \mathrm{sec}$, and extension at $72^{\circ} \mathrm{C}$ for $50 \mathrm{sec}$, and 39 cycles of denaturation at $95^{\circ} \mathrm{C}$ for $50 \mathrm{sec}$, annealing at $55^{\circ} \mathrm{C}$ for $50 \mathrm{sec}$ and extension at $72^{\circ} \mathrm{C}$ for $50 \mathrm{sec}$, followed by a final extension step of $2 \mathrm{~min}$ at $72^{\circ} \mathrm{C}$. ACTN3 exon 16 was amplified by PCR using ACTN3 forward and reverse primers (Table I; Tib MolBiol Syntheselabor $\mathrm{GmbH})$. PCR was performed at $95^{\circ} \mathrm{C}$ for $5 \mathrm{~min}, 35$ cycles of denaturation at $95^{\circ} \mathrm{C}$ for $30 \mathrm{sec}$, annealing at $60^{\circ} \mathrm{C}$ for $30 \mathrm{sec}$ and extension at $72^{\circ} \mathrm{C}$ for $30 \mathrm{sec}$, and a final extension step for $10 \mathrm{~min}$ at $72^{\circ} \mathrm{C}$. The resulting ACTN3 gene PCR products were genotyped (in the Human Diseases and Diagnosis Laboratory, Istanbul University, Istanbul, Turkey) by restriction fragment length polymorphism using DdeI restriction enzyme (Tib MolBiol Syntheselabor GmbH). Products were separated by a bioanalyser (Agilent 1000; Agilent Technologies, Inc.).

\section{Results}

Bioanalyser results. Each genotype of the ACTN3 gene was characterised using the bioanalyser. The XX genotype (Fig. 1)

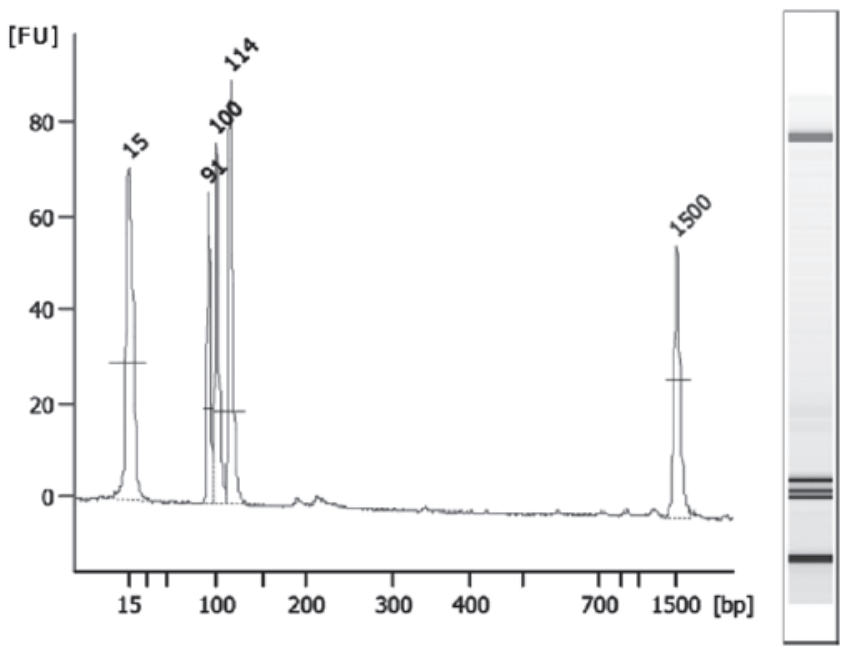

Figure 1. Bioanalyser results for the ACNT3 XX genotype. Three peaks were detected . bp, base pairs; FU, fluorescence units; ACNT3, $\alpha$-actinin-3.

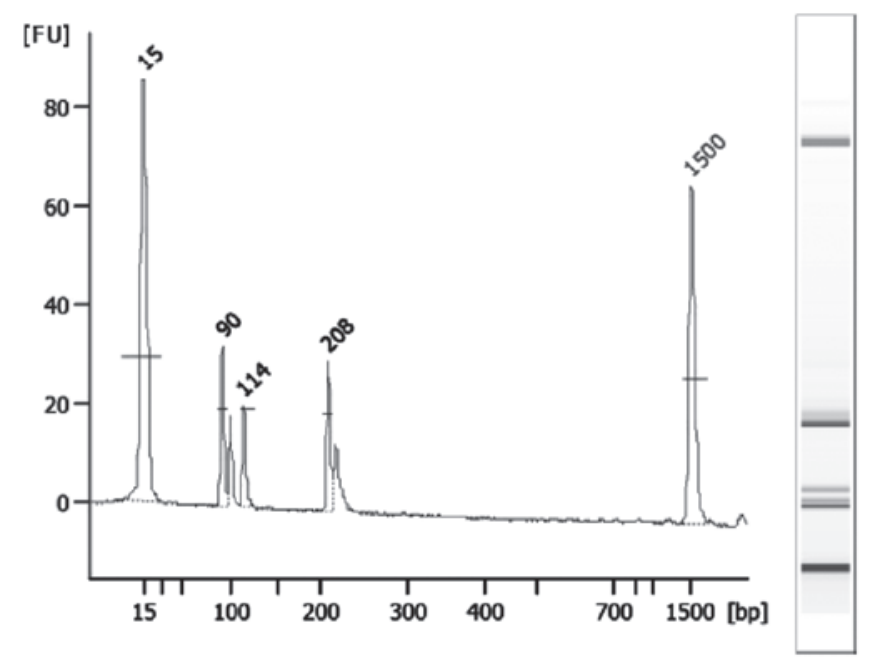

Figure 2. Bioanalyser results for the ACNT3 RX genotype. The peaks at $15 \mathrm{bp}$ and $1500 \mathrm{bp}$ are the upper and lower markers. The other peaks (90, $97,114 \mathrm{bp}$ and $208 \mathrm{bp}$ ) are similar to the findings of Ginevičienè et al (19), which indicates that these results show the RX genotype. bp, base pairs; FU, fluorescence units; ACNT3, $\alpha$-actinin-3.

exhibited three peaks (86, 97 and $108 \mathrm{bp})$, the RX genotype (Fig. 2) four peaks (86, 97, 108 and 205 bp) and the RR genotype (Fig. 3) two peaks (86 and 205 bp). With regard to the ACE gene, the DD genotype exhibited one peak at $180 \mathrm{bp}$ 
Table II. Number and frequency (\%) of ACE genotypes in the elite athletes and controls.

\begin{tabular}{lccc}
\hline & \multicolumn{3}{c}{ Genotype } \\
\cline { 2 - 4 } Group (n) & DD & ID & II \\
\hline Controls (37) & $14(37.84)$ & $11(29.73)$ & $12(32.43)$ \\
Elites (37) & $19(51.35)$ & $15(40.54)$ & $3(8.11)$
\end{tabular}

ACE, angiotensin I-converting enzyme.

Table III. Number and frequency (\%) of ACTN3 genotypes in the elite athletes and controls.

\begin{tabular}{lccc}
\hline & \multicolumn{3}{c}{ Genotype } \\
\cline { 2 - 4 } Group (n) & $\mathrm{RR}$ & $\mathrm{RX}$ & $\mathrm{XX}$ \\
\hline Controls (37) & $1(2.70)$ & $32(86.48)$ & $4(10.81)$ \\
Elites (37) & $4(10.81)$ & $20(54.05)$ & $13(35.14)$ \\
\hline
\end{tabular}

ACNT3, $\alpha$-actinin-3.

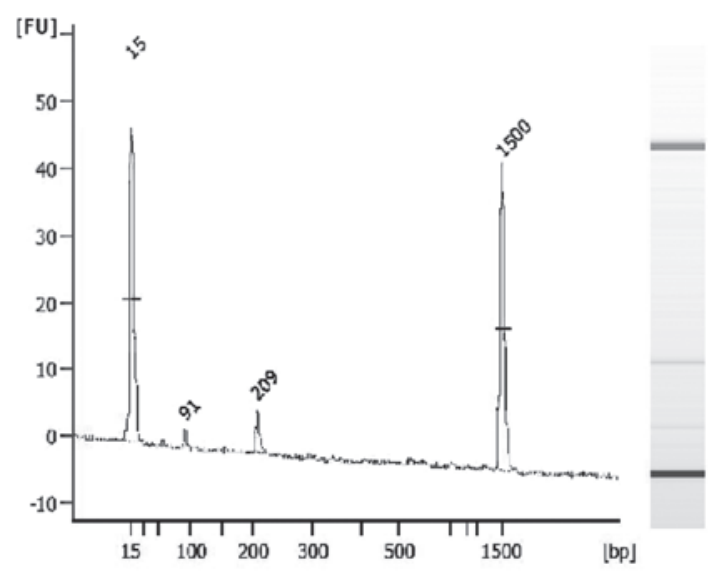

Figure 3. Bioanalyser results for the ACNT3 RR genotype. Two peaks were detected. bp, base pairs; FU, fluorescence units; ACNT3, $\alpha$-actinin-3.

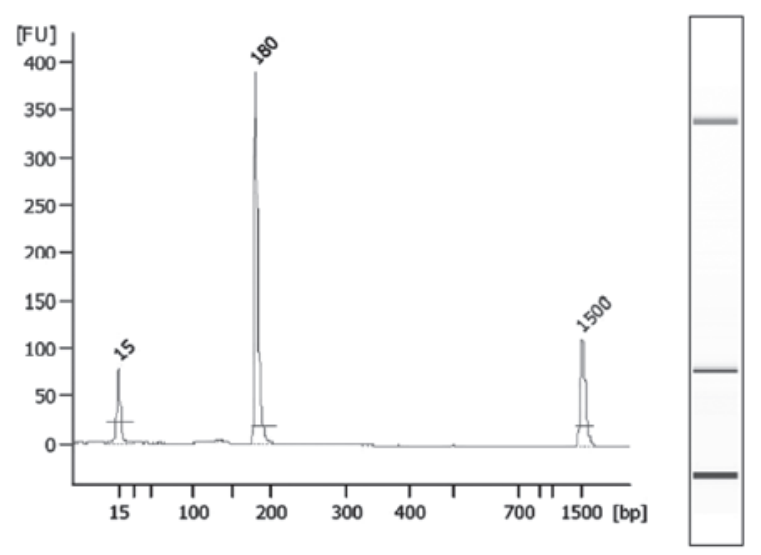

Figure 4. Bioanalyser results for the ACE DD genotype. One peak was detected at 180 bp. bp, base pairs; FU, fluorescence units; ACE, angiotensin I-converting enzyme.

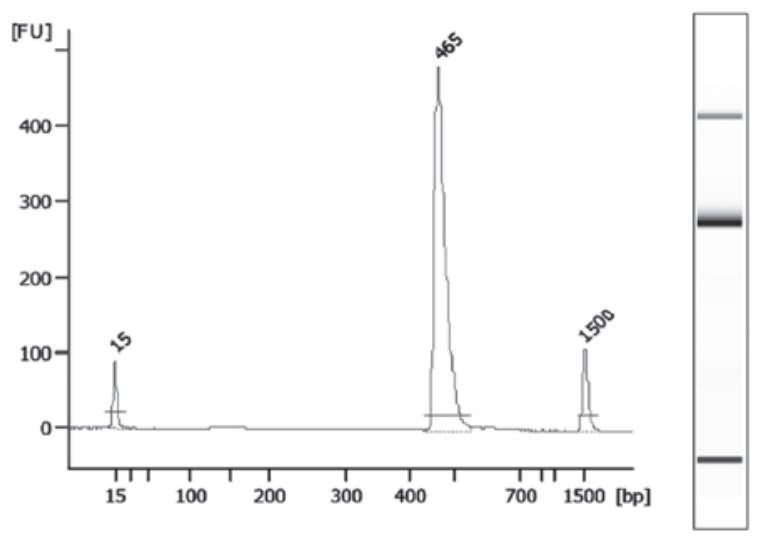

Figure 5. Bioanalyser results for the angiotensin I-converting enzyme II genotype. One peak was detected. bp, base pairs; FU, fluorescence units.

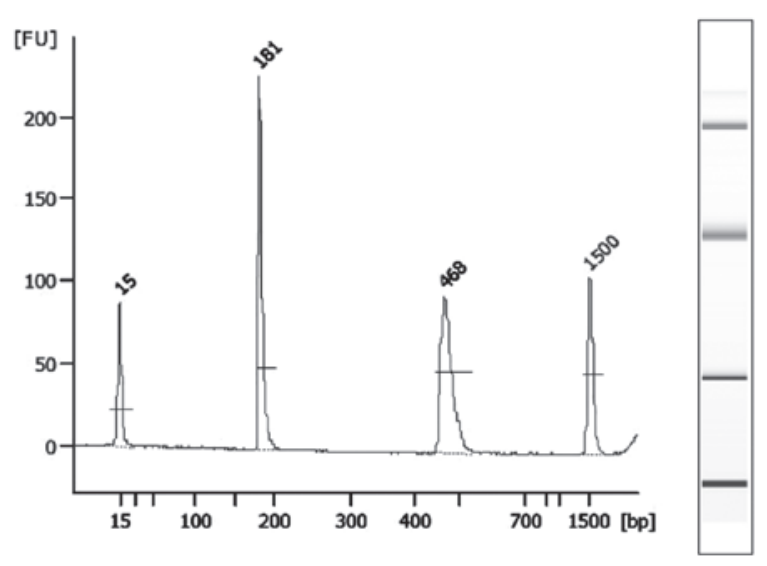

Figure 6. Bioanalyser results for the ACE ID genotype. Two peaks were detected. bp, base pairs; FU, fluorescence units; ACE, angiotensin I-converting enzyme.

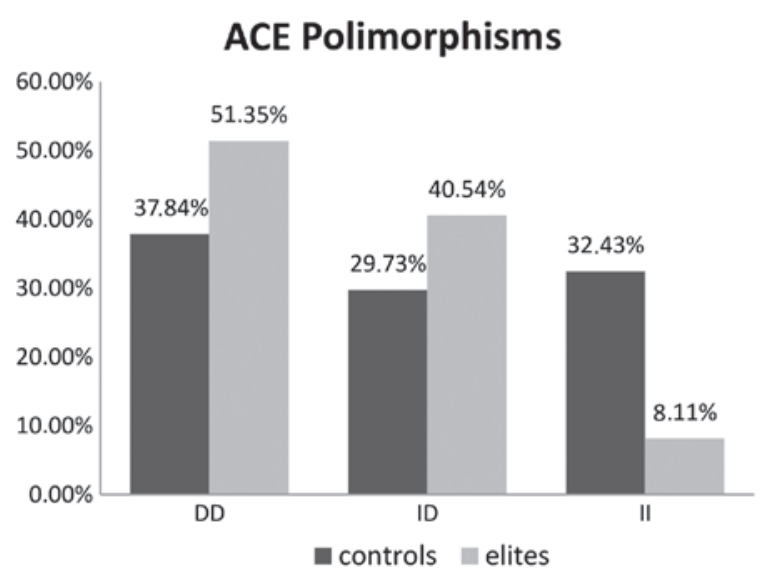

Figure 7. Comparison of ACE polymorphism frequencies between the elite athletes and the controls. ACE, angiotensin I-converting enzyme.

(Fig. 4), the II genotype one peak at 490 bp (Fig. 5) and the ID genotype two peaks at 180 and 490 bp (Fig. 6).

Genotype frequencies. The ACE I/D genotype frequencies in the elite athletes and the control group are shown in Table II and Fig. 7. The frequencies of the ACTN3 R577X genotypes 
Table IV. Number and frequency (\%) of ACTN3 and ACE genotypes in the elite athletes and controls.

\begin{tabular}{lccccccccc}
\hline & \multicolumn{7}{c}{ Genotype (ACTN3/ACE) } \\
\cline { 2 - 9 } Group (n) & RR/II & RR/ID & RR/DD & RX/II & RX/ID & RX/DD & XX/II & XX/ID & XX/DD \\
\hline Controls (37) & 0 & $1(2.70)$ & 0 & $11(29.73)$ & $8(21.62)$ & $13(35.14)$ & $1(2.70)$ & $2(5.41)$ & $1(2.70)$ \\
Elites (37) & 0 & $1(2.70)$ & $3(8.11)$ & $2(5.41)$ & $9(24.32)$ & $9(24.32)$ & $1(2.70)$ & $5(13.51)$ & $7(18.92)$
\end{tabular}

ACTN3, $\alpha$-actinin-3; ACE, angiotensin I-converting enzyme.

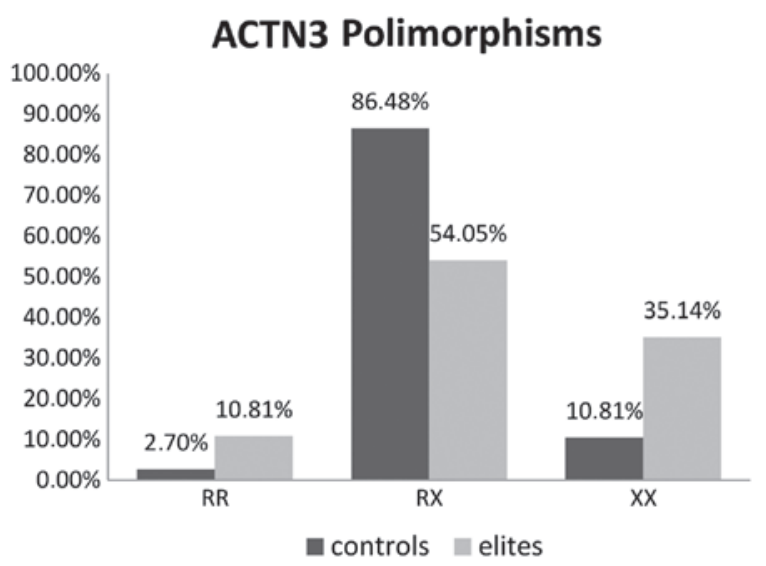

Figure 8. Comparison of ACTN3 polymorphism frequencies in the elite athlete and control groups. ACTN3, $\alpha$-actinin-3.

\section{ACE and ACTN3 Gene Polymorphisms in Elite Athletes}

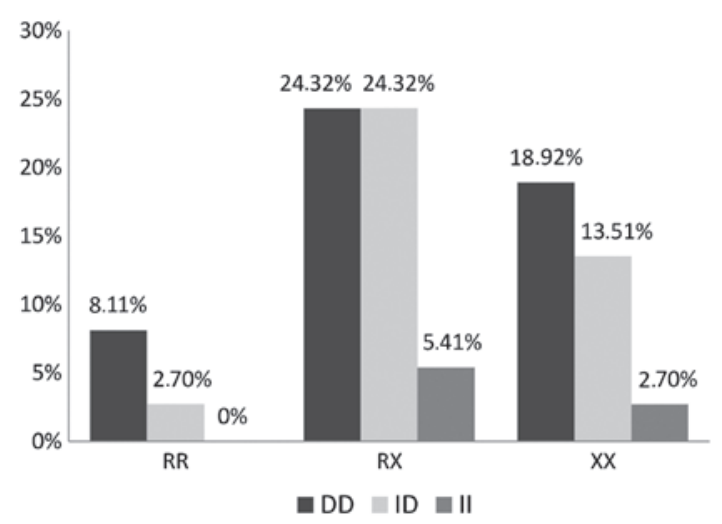

Figure 9. Comparison of ACE and ACTN3 polymorphisms in the elite athlete group. ACE, angiotensin I-converting enzyme; ACTN3, $\alpha$-actinin-3.

are compared in Table III and Fig. 8. The complete data on the genotype frequencies in the elite and control subjects are shown in Table IV. The number and frequencies of the combined ACE and ACTN3 genotypes in the elite athlete and control groups are compared in Figs. 9 and 10, respectively.

\section{Discussion}

Sport performance is likely to be polygenic due to the combined effect of hundreds of points of genetic variance among individuals. One possible variation that affects sports

\section{ACE and ACTN3 Gene Polymophisms in Control Group}

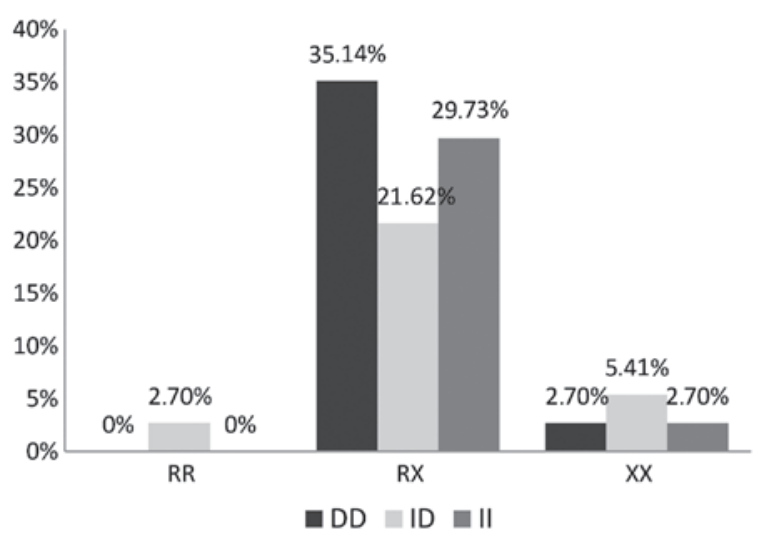

Figure 10. Comparison of ACE and ACTN3 polymorphisms in the control group. ACE, angiotensin I-converting enzyme; ACTN3, $\alpha$-actinin-3.

performance is the ACE polymorphism, and another is the ACTN3 polymorphism. The aim of the present study was to analyse the frequency of the polymorphisms of these two genes.

ACE is a key component in the renin-angiotensin-aldosterone system, generating vasoconstrictor angiotensin II and degrading vasodilator kinins (2). ACE is widely expressed in skeletal muscle and other human tissues and may be involved in metabolism during exercise (13-15). A 287-base pair insertion (I) in an Alu intronic region of chromosome 17 has been associated with improved performance in endurance sports, and the corresponding absence of this segment (D) has been associated with improved performance in strength- and power-oriented sports (16). A previous study reported a close similarity in the distribution of genotypes between athletes and control subjects, identifying the following frequencies of genotypes: DD, 30.0 and $29.0 \%$; ID, 47.5 and $49.0 \%$; and II, 22.5 and $22.0 \%$, for athletes and controls respectively (17). In the present study, the DD genotype (which is advantageous for sprinting) was detected at a higher level in the elite athletes $(51.35 \%)$ than that in the control group (37.84\%). The frequency of the II genotype (which has been shown to benefit endurance) was higher in the control group (32.43\%) than that in the elite athletes $(8.11 \%)$. The ID genotype frequency was higher in the elite athletes $(40.54 \%)$ than that in the control group (29.73\%).

The ACTN2 and ACTN3 genes encode the skeletal muscle proteins $\alpha$-actinin- 2 and $\alpha$-actinin-3, respectively (11). 
The first association study to investigate the influence of ACTN3 genotypes on athletic performance was published by Yang et al (11) in 2003. A previous study reported that the frequency of the RR genotype was significantly higher in soccer players $(48.3 \%)$ than that in controls $(28.5 \%)$ or endurance athletes $(26.5 \%)$, and the frequency of the RX genotype was significantly lower in the soccer players (36.7\%) compared with that of the controls (53.7\%) and endurance athletes $(52.0 \%)(\mathrm{P}=0.041)$. Although there are a notable number of exceptions, elite soccer players tend to have the sprint/power ACTN3 genotype (18). In the present study, the RR (associated with the sprinter property) and XX (associated with the endurance property) genotypes were detected at higher frequencies in elite athletes (10.81 and $35.14 \%$, respectively) than in the controls (2.70 and $10.81 \%$, respectively). The frequency of the RX genotype was higher in the control group (86.48\%) than that in the elite athletes (54.05\%).

The ACE I and ACTN3 X alleles influence speed and power in athletes. Athletes with the ACE I/I and I/D genotypes, as well as the ACTN3 X/X and R/X genotypes, have the potential to achieve improved results in sports requiring power; therefore, analysing the polymorphisms of these genes may be useful in sport type selection (19). However, Myerson et al (4) found that the ACE genotype was not a key determinant of success in the best sprinters worldwide and suggested that the $\mathrm{D}$ allele is more common among sprinters. The present study demonstrated that the ACE DD/ACTN3 RR genotype combination is detected at a higher frequency in elite athletes $(8.11 \%)$ than that in controls (0\%). The ACE DD/ACTN3 XX genotype combination was also identified at a higher frequency in the elite group (18.92) than that in the control group (2.70\%). These results are in accordance with those of Eynon et al (20). The frequency of the ACE I allele (present in the ACE II and ACE ID genotypes) and ACTN3 XX genotype combination was higher in the elite athlete group (16.21\%) than that the control group $(8.11 \%)$. This genotype was therefore identified as enhancing endurance activity performance.

In conclusion, the findings of the present study suggest a novel mechanism involving the renin-angiotensin-aldosterone system, in the response of skeletal muscle fast or slow contraction. However, the aforementioned genotype combination is not associated with the level of performance. Therefore it is difficult to interpret the meaningful results because of the various populations and ethnic groups.

\section{Acknowledgements}

This study was supported by the Scientific and Technological Research Council of Turkey (project no: 2209A/2012) and the Research Foundation of the University of Istanbul (project no: $25814 / 2012$ ).

\section{References}

1. Ma F, Yang Y, Li X, Zhou F, Gao C, Li M and Gao L: The association of sport performance with ACE and ACTN3 genetic polymorphisms: a systematic review and meta-analysis. PloS One 8: e54685, 2013.

2. Coates D: The angiotensin converting enzyme (ACE). Int J Biochem Cell Biol 35: 769-773, 2003.

3. Montgomery HE, Marshall R, Hemingway H, et al: Human gene for physical performance. Nature 393: 221-222, 1998.

4. Myerson S, Hemingway H, Budget R, Martin J, Humphries S and Montgomery $\mathrm{H}$ : Human angiotensin I-converting enzyme gene and endurance performance. J Appl Physiol (1985) 87: 1313-1316, 1999.

5. Bray MS, Hagberg JM, Pérusse L, et al: The human gene map for performance and health-related fitness phenotypes: the 2006-2007 update. Med Sci Sports Exerc 41: 35-73, 2009.

6. Ahmetov II and Rogozkin VA: Genes, athlete status and training - An overview. Med Sport Sci 54: 43-71, 2009.

7. Ahmetov II, Druzhevskaya AM, Lyubaeva EV, Popov DV, Vinogradova OL and Williams AG: The dependence of preferred competitive racing distance on muscle fibre type composition and ACTN3 genotype in speed skaters. Exp Physiol 96: 1302-1310, 2011.

8. Mills M, Yang N, Weinberger R, et al: Differential expression of the actin-binding proteins, alpha actinin-2 and -3 , in different species: implications for the evolution of functional redundancy. Hum Mol Genet 10: 1335-1346, 2001.

9. North KN, Yang N, Wattanasirichaigoon D, et al: A common nonsense mutation results in alpha-actinin-3 deficiency in the general population. Nat Genet 21: 353-354, 1999.

10. Collins M (ed): Genetics and Sports. Karger, Basel, pp43-101, 2009.

11. Yang N, MacArthur DG, Gulbin JP, Hahn AG, Beggs AH, Easteal S and North K: ACTN3 genotype is associated with human elite athletic performance. Am J Hum Genet 73: 627-631, 2003.

12. Lippi G, Longo UG and Maffulli N: Genetics and sports. Br Med Bull 93: 27-47, 2010.

13. Jones A and Woods DR: Skeletal muscle RAS and exercise performance. Int J Biochem Cell Biol 35: 855-866, 2003.

14. Danser AH, Schalekamp MA, Bax WA, van den Brink AM, Saxena PR, Riegger GA and Schunkert H: Angiotensin-converting enzyme in the human heart. Effect of the deletion/insertion polymorphism. Circulation 92: 1387-1388, 1995.

15. Rigat B, Hubert C, Alhenc-Gelas F, Cambien F, Corvol P and Soubrier F: An insertion/deletion polymorphism in the angiotensin I-converting enzyme gene accounting for half the variance of serum enzyme levels. J Clin Invest 86: 1343-1346, 1990.

16. Woods DR, Humphries SE and Montgomery HE: The ACE I/D polymorphism and human physical performance. Trends Endocrinol Metab 11: 416-420, 2000.

17. Taylor RR, Mamotte CD, Fallon K and van Bockxmeer FM: Elite athletes and the gene for angiotensin-converting enzyme. J Appl Physiol (1985) 87: 1035-1037, 1999.

18. Santiago C, González-Freire M, Serratosa L, Morate FJ, Meyer T, Gómez-Gallego F and Lucia A: ACTN3 genotype in professional soccer players. Br J Sports Med 42: 71-73, 2008.

19. Ginevičienè V, Pranculis A, Jakaitienè A, Milašius K and Kučinskas V: Genetic variation of the human ACE and ACTN3 genes and their association with functional muscle properties in Lithuanian elite athletes. Medicina (Kaunas) 47: 284-290, 2011.

20. Eynon N, Alves AJ, Yamin C, et al: Is there an ACE ID - ACTN3 R577X polymorphisms interaction that influences sprint performance? Int J Sports Medicine 30: 888-891, 2009. 